\title{
Sage Essential Oil Improves the Effectiveness of Aloe vera Gel on Postharvest Quality of Tomato Fruit
}

\author{
Nikolaos Tzortzakis *, Panayiota Xylia and Antonios Chrysargyris * \\ Department of Agricultural Sciences, Biotechnology and Food Science, Cyprus University of Technology, \\ Limassol 3603, Cyprus; pa.xylia@edu.cut.ac.cy \\ * Correspondence: nikolaos.tzortzakis@cut.ac.cy (N.T.); a.chrysargyris@cut.ac.cy (A.C.)
}

Received: 23 September 2019; Accepted: 11 October 2019; Published: 14 October 2019

\begin{abstract}
Edible coating is extensively applied for fresh produce preservation. In the present study, Aloe vera gel (AV) alone or combined with sage essential oil (EO; $0.1 \%$ or $0.5 \%$ ) was used as fruit edible coating in tomatoes. Following treatments, tomatoes were stored at $11^{\circ} \mathrm{C}$ and $90 \%$ relative humidity (RH) up to 14 days and analyzed for quality maintenance compared with uncoated fruits (control). Results showed that both $\mathrm{AV}$ and EO decreased decay symptoms with more pronounced effects on low EO concentration (i.e., $0.1 \%$ ). The application of $10 \%$ of $\mathrm{AV}$ coating decreased fruit ethylene emission while EO $(0.1 \%$ and $0.5 \%)$ application increased ethylene emission and respiration rates. AV coating decreased acidity, $\beta$-carotene, lycopene content and maintained fruit firmness. High levels of EO $(0.5 \%)$ increased weight loss but decreased fruits' redness, chroma, total soluble solids, acidity, $\beta$-carotene and lycopene content. Total phenolic content and antioxidants maintained or increased during storage when treated with $\mathrm{AV}$ and/or EO. Low levels of $\mathrm{EO}(0.1 \%)$ maintained or improved fruit quality characteristics during storage, and this was mirrored by the sensory evaluation preference (including the AV application) and quality related attributes.
\end{abstract}

Keywords: edible coating; sage oil; Aloe vera; preservation; quality-related attributes; tomato

\section{Introduction}

Due to the well-known organoleptic and nutritious properties, including bioactive compounds with antioxidant and anticarcinogen activities, tomato (Solanum lycopersicum L.) fruit is extremely valued by consumers [1-3]. Tomato is a climacteric fruit and deteriorates rapidly after harvest with a quite short postharvest life, ranging from several days to 2-3 weeks, depending on the cultivar and the preservation mean [4]. After harvesting, the quality of tomatoes continuously changes with great losses due to increased rates of respiration and transpiration, postharvest decay and speed-up of metabolic processes of ripening and senescence [5].

Commonly, tomatoes are stored at low temperatures ranging from $11-13{ }^{\circ} \mathrm{C}[4,6,7]$, as this is generally used to slow down ripening metabolic processes and delay postharvest deterioration, even if this treatment is not sufficient in most cases to preserve fruit quality and safety during the postharvest chain. Lately, the increase in the consumption of fresh fruit and vegetables together with the increase in postharvest losses of commodities has alarmed to define new practices for sustainable postharvest management. Therefore, storage and transit conditions of fresh produce, management of postharvest diseases and maintenance of the quality of fruit (i.e., flavor, color, dietary value, firmness, shelf life and processing characteristics) need improvements [8]. Osei et al. [9] reviewed the recent advance technique on RNA interference that can be used to down regulate the genes involved in ethylene biosynthesis and cell-wall degrading enzymes to extend the shelf life in tomato. Chemical treatments are used for produce preservation but several health and environmental concerns over the effectiveness and the risk of producing possibly harmful bi-products and residues of the current practices are 
questionable [10]. Therefore, additional postharvest tools, combined with chilled storage are needed. Both physical means (ozone, electrolyzed water and modified/controlled atmospheric packaging) and natural compounds (chitosan, essential oils, biocontrol agent, antifungal edible coatings and organic acids) are attracting research interest as alternative, safe, but efficient preservation means in the fresh produce industry [11-16]. The use of natural components for edible coating applications is referenced as a safer option for extending the shelf life of perishable fresh produce and improving food appearance [17,18].

Among the natural compounds, Aloe vera (AV) is a fitting successive postharvest application for an edible coating for fresh commodities like table grapes [19,20], strawberries [21], tomatoes [6,22], apples [23], peaches, plums and nectarines [24] and sweet cherries [25], to name a few. Coatings with AV preserved quality-related parameters such as color, texture and acidity, and decreased the production of ethylene and respiration rate (especially in climacteric fruit), prolonging the fresh produce storability. Usually, in these researches, the A. vera concentration ranged from $50 \%$ to $100 \%$, although it was much smaller for apples $(0 \%-10 \%)$ and tomatoes $(0 \%-20 \%)$. The gel of AV has been recognized as an innovative antimicrobial coating agent [26-28] associated with aloin content, one of the main phenolic components of Aloe plants [29].

Aloe vera gel is rich in polysaccharides and soluble sugars but has low lipids levels $(0.07 \%-0.42 \%)$ and low hydrophobic properties as an edible coating material [29]. This way, the hydrophobic properties and the gas barrier efficacy of AV-based edible coatings can be enhanced by adding lipids as a constitute on edible coating applications [30]. To that direction, essential oils (EO) from aromatic plants species, being an economic source of unsaturated fatty acids, posing antimicrobial and antioxidant activities, can be used for edible coating of fresh produce [31-33]. Sage (Salvia spp.) is a wide cultivated plant species and its essential oil has been applied for postharvest preservation in pepper (EO from Salvia fruticosa L.; Tzortzakis et al. [34]), and in apricot, nectarine and plum (EO from Salvia officinalis L; Lopez-Reyes et al., [35]). There is no proof, however, that sage oil is used to preserve tomatoes during postharvest storage. Therefore, the aim of this research was to evaluate the positive impacts of adding sage oil to $\mathrm{AV}$ gel on delaying the ripening process and preserving tomato quality.

\section{Materials and Methods}

\subsection{Plant Material and Experimental Design}

Aloe vera was freshly prepared as described previously [6]. Briefly, the spikes along their edges were separated for each leaf in order to separate the rind from the inner leaf gel before longitudinally slicing. The gel was then filtered to remove the fibrous fraction and diluted using distilled water to the concentration of $10 \%(v / v)$.

Tomatoes (cv. Daphne F1) were harvested from organic field cultivation located in Limassol, Cyprus. Daphne F1 is an early hybrid with high productivity, indeterminate, plant with optimal vigor, stress tolerance, good setting, long self-life (LSL) and bright red fruits of 160-200 g. Tomato crop was grown under common cultivation practices in a clay sandy-loam soil and drip irrigation was applied according to crop needs. The cultivation took place during spring months and the temperature ranged between $19{ }^{\circ} \mathrm{C}$ and $29^{\circ} \mathrm{C}$. Fruits were harvested from the 2nd and 3rd inflorescences of the plants and transferred to the laboratory within $1 \mathrm{~h}$. Homogeneous batches of fruits based on color, size, red-ripe stage and absent from defect or injury were selected and further used for the needs of the study. Fruits were immersed in diluted chlorine $(0.05 \%)$ solution for $4 \mathrm{~min}$ and washed four times using distilled water, in a way to avoid any microbial load.

Essential oils derived from organically grown sage (Salvia fruticosa L. (Lamiaceae)), harvested from the same region as the tomato crop, were extracted for $3 \mathrm{~h}$, using a Clevenger type water-steam distillation system. The analysis of the EO, which was carried out using gas chromatography-mass spectroscopy (GC-MS), and the identification of the compounds were performed as described previously [36]. 
Tomatoes were immersed in coating solution for $10 \mathrm{~min}$ [6]. The following six treatments were examined: (i) purified water (control), (ii) $10 \%$ A vera gel solution, (iii) $\mathrm{EO}$ at $0.1 \%$, (iv) $10 \%$ A vera gel solution with $0.1 \% \mathrm{EO}$, (v) EO at $0.5 \%$ and (vi) $10 \%$ A. vera gel solution with $0.5 \% \mathrm{EO}$. Mixtures of $A$. vera gel and EO were prepared by dissolving the sage oil in water, with the use of Tween- 80 , followed by the addition of the gel under vigorous shaking. Tomatoes were immersed and coated uniformly by the examined solution. Following treatment, fruits have been left to dry for $20 \mathrm{~min}$ at room temperature. Then, each two fruits were placed into polystyrene, snap-on lid containers of $1 \mathrm{~L}$. In total, eight biological replications (eight containers) per treatment, for each storage period of 7 and $14 \mathrm{~d}$, were prepared. Containers were placed in chamber at $11^{\circ} \mathrm{C}$ and $90 \%$ relatively humidity (RH $\sim 90 \%$ ), in darkness. Summarizing, the experimental set up was consisted of six treatments $\times$ eight replications (two fruits per replication) $\times$ two storage periods (plus day 0 ) with a total of 208 fruits used. To maintain high RH during storage period, wet filter paper was displaced in a small glass tube inside each container, and was remoistened every second day [6]. Containers lids were open every 48 $\mathrm{h}$ and aerated in order to avoid air concentration abnormalities. No phytotoxic effect on tomato fruit observed following coating applications.

\subsection{Decay Evaluation}

Fruit decay was visually evaluated at day 7 and 14 , after storage at $1{ }^{\circ} \mathrm{C}$. All fruits from each container were used for the evaluation. A fruit was considered as decayed when the development of surface mycelia was showed. A scale from 1 to 5 (1-no infection, 2-trace infection, 3-slight infection, 4-moderate infection and 5-severe infection) was assessed to estimate the degree of fruit infection. Tomato tissue was then cultured in PDA (potato dextrose agar) for rot discrimination [37].

\subsection{Respiration Rate and Ethylene Emission}

The carbon dioxide $\left(\mathrm{CO}_{2}\right)$ and ethylene production were assessed by placing each fruit in a $1 \mathrm{~L}$ glass container sealed with a rubber stopper for $1 \mathrm{~h}$, at room temperature. Fruits were weighed and volume was measured. Moreover, $\mathrm{CO}_{2}$ and ethylene of room air were tested and subtracted from the measurements, by equipment zeroing, prior to and during experimentation. For the respiration rate determination, container gas atmosphere was sucked by a dual gas analyzer (GCS 250 Analyzer, International Control Analyser Ltd., Kent, UK) for $30 \mathrm{~s}$ and results expressed as milliliter of $\mathrm{CO}_{2}$ per kilogram per hour. Ethylene was measured with an ethylene analyzer (ICA 56 Analyzer, International Control Analyser Ltd., Kent, UK) whereas the container air sample was sucked for $30 \mathrm{~s}$. Results were expressed as microliter of ethylene per kilogram per hour (eight jars per treatment and storage period; $n=8)$.

\subsection{Weight Loss, Color and Fruit Firmness}

Fruit weight was recorded on the harvesting day (day 0 ) and after the different sampling dates. Weight loss was calculated for each fruit $(n=8)$ per treatment and storage time.

Color was measured using the Hunter Lab System and a Minolta colorimeter model CR400 (Konica Minolta, Osaka, Japan). Following the recording at four points along the equatorial axis on each tomato for the individual $L^{*}, a^{*}$, and $b^{*}$ parameters, chroma value $(C)$ and hue $(h)$ were calculated by the following equations $C=\left(a^{* 2}+b^{* 2}\right)^{1 / 2}$, and $h=b^{*} / a^{*}$ as described previously [38].

Fruit firmness was measured at two points on the shoulder of each tomato fruit by applying a plunger of $8 \mathrm{~mm}$ in diameter, using a texturometer FT 011 (TR Scientific Instruments, Forli, Italy). The amount of force (in Newtons; N) required to break the radial pericarp (i.e., surface) of each tomato $(n=8)$ was recorded at ambient temperature $\left(22-24{ }^{\circ} \mathrm{C}\right)$.

\subsection{Soluble Solids, Titratable Acidity, Ascorbic Acid and Carotenoids}

Total soluble solids (TSSs) concentration was determined in duplicate from the juice obtained from two pooled tomatoes for each replication $(n=8)$ with a temperature-compensated digital refractometer 
(model Atago PR-101, Atago Co. Ltd., Tokyo, Japan) at $20^{\circ} \mathrm{C}$, and results were expressed in percentage (\%). The titratable acidity (TA) was measured via potentiometric titration (Mettler Toledo DL22, Columbus, $\mathrm{OH}, \mathrm{USA}$ ) of $5 \mathrm{~mL}$ juice diluted to $50 \mathrm{~mL}$ with distilled water using $0.1 \mathrm{~N} \mathrm{NaOH}$ up to $\mathrm{pH}$ 8.1. Results were expressed as percentage of citric acid. The ratio of TSS/TA was used to evaluate the sweetness of the fruit.

Ascorbic acid (consisting the major part in vitamin C) was determined by the 2,6-dichloroindophenol titrimetric method [39]. An aliquot of $5 \mathrm{~mL}$ of pooled tomato juice was diluted with $5 \mathrm{~mL}$ of water and was titrated by the dye solution until the color changed. Data was expressed as $\mathrm{mg}$ of ascorbic acid per gram of fresh weight.

Carotenoids (lycopene and $\beta$-carotene) were determined according to the Nagata and Yamashita [40] following modification [6]. Thus, $1 \mathrm{~g}$ of blended tomatoes were placed in $50 \mathrm{~mL}$ falcons and $16 \mathrm{~mL}$ of acetone:hexane 4:6 (v:v) were added to each sample, the samples were shaken vigorously and the two phases were separated automatically. An aliquot was taken from the upper solution for measurement of optical density at $663,645,505$ and $453 \mathrm{~nm}$ in a spectrophotometer, using a reference acetone:hexane (4:6) ratio. Lycopene and $\beta$-carotene contents were calculated according to the Nagata and Yamashita [40] equations:

Lycopene $\left(\mathrm{mg} 100 \mathrm{~mL}^{-1}\right.$ of extract $)=-0.0458 \times \mathrm{A} 663+0.204 \times \mathrm{A} 645+0.372 \times \mathrm{A} 505-0.0806 \times \mathrm{A} 453$.

$\beta$-Carotene $\left(\mathrm{mg} 100 \mathrm{~mL}^{-1}\right.$ of extract $)=0.216 \times \mathrm{A} 663-1.22 \times \mathrm{A} 645-0.304 \times \mathrm{A} 505+0.452 \times \mathrm{A} 453$.

Results were expressed as nmol per gram of fresh weight.

\subsection{Total Phenolics and Antioxidant Activity}

Total phenolics were determined using methanolic extracts of the tomato fruits, as previously described by Tzortzakis et al. [41] and results were expressed as $\mu \mathrm{mol}$ of gallic acid equivalents (GAE) per gram of fresh weight. Antioxidant capacity was determined by ferric-reducing antioxidant power (FRAP) and 2,2-diphenyl-1-picrylhydrazyl (DPPH) radical-scavenging activity assays as described previously [32]. The results were expressed in $\mathrm{mg}$ trolox per gram of fresh weight. All samples were analyzed in triplicate.

\subsection{Sensory Evaluation}

Sensory analyses was performed by 10 panelists, to compare the external visual aspect and marketability of treated and control tomato fruit after 7 and 14 days of storage at $11^{\circ} \mathrm{C}$, similar ratio of males and females (aged from 21 to 42 years old). The panel was trained prior to the sensory evaluation of the tomato fruit. The panel initially assessed the preferences in treatments. For that, individual panelists were challenged to evaluate more than one fruit from each sample to ensure representative results. Panelists asked to assess appearance, color, aroma, sweetness, texture and marketability using scales (values of acceptance) with anchor points 1: 'Poor/unsweet/soft' and 5: 'excellent/very sweet/firm'. Records were converted to percentage values. Individual panelists were presented with six plates (one representing each treatment) containing two whole tomato fruit and two halved-fruit for the sensory evaluation, with all tests conducted under the same conditions and without time limit. Panel tests were conducted in isolation in booths in the same room to prevent interchange between panel members.

\subsection{Statistical Analysis}

Data were subjected to analysis of variance (ANOVA) and prior to that were tested for normality. Variables were storage period and preservation treatments. Significant differences between mean values were determined using Duncan's Multiple Range Test $(p=0.05)$ following one-way ANOVA. Statistical analyses were performed using SPSS (SPSS Inc., Chicago, IL, USA). Pairwise metabolites effects correlations were calculated by Pearson's correlation test using the R program. 


\section{Results}

Sage EO composition is illustrated in Table 1, and analysis revealed the presence of thirty-two individual compounds, representing the $\geq 99.30 \%$ of the total oil profile. Oxygenated monoterpenes compounds were the most abundant class (averaged in $71.29 \%$ ) followed by monoterpenes hydrocarbon (averaged in $17.01 \%$ ), sesquiterpenes hydrocarbons (averaged in $4.93 \%$ ) and oxygenated sesquiterpenes (averaged in 4.68\%; Table 1). The major components of the examined sage EO in decreasing order were $\alpha$ thujone $(27.17 \% \pm 0.15 \%)$, eucalyptol $(17.502 \% \pm 0.036 \%)$, camphor $(16.909 \% \pm 0.061 \%), \beta$ thujone $(6.854 \% \pm 0.014 \%)$, viridiflorol $(4.484 \% \pm 0.006 \%)$, camphene $(4.735 \% \pm 0.054 \%), \beta$ pinene $(3.019 \% \pm$ $0.038 \%), \alpha$ pinene $(2.513 \% \pm 0.039 \%), \beta$ caryophyllene $(2.323 \% \pm 0.000 \%), \beta$ myrcene $(2.836 \% \pm 0.036 \%)$, borneol $(1.435 \% \pm 0.006 \%)$ and limonene $(1.428 \% \pm 0.009 \%)$, while other components were found in levels less than $1 \%$ of the total oil profile. The major components of the EO ( $\alpha$ thujone, eucalyptol and camphor) have been referenced to exhibit antimicrobial and antioxidant activities, indicating sage EO as a natural preservation mean for fresh produce storage [33]. Additionally, the antimicrobial properties of AV gel are also well documented [27,28].

Table 1. Chemical composition (\%) of essential oils of sage plants.

\begin{tabular}{|c|c|c|c|c|c|}
\hline Compound & RI & $(\%)$ & Compound & RI & $(\%)$ \\
\hline Tricyclene & 921 & $0.152 \pm 0.002$ & Borneol & 1166 & $1.435 \pm 0.006$ \\
\hline$\alpha$ Thujene & 926 & $0.347 \pm 0.005$ & Terpinen-4-ol & 1177 & $0.634 \pm 0.000$ \\
\hline$\alpha$ Pinene & 933 & $3.019 \pm 0.038$ & $\alpha$ Terpineol & 1191 & $0.122 \pm 0.000$ \\
\hline Camphene & 948 & $4.735 \pm 0.054$ & Carvone & 1244 & $0.040 \pm 0.002$ \\
\hline Sabinene & 973 & $0.132 \pm 0.002$ & Iso Bornyl acetate & 1284 & $0.459 \pm 0.001$ \\
\hline$\alpha$ Pinene & 977 & $2.513 \pm 0.039$ & $\beta$ Caryophyllene & 1425 & $2.323 \pm 0.000$ \\
\hline$\beta$ Myrcene & 989 & $2.836 \pm 0.036$ & $\gamma$ Elemene & 1444 & $0.160 \pm 0.002$ \\
\hline$\alpha$ Phellandrene & 1004 & $0.045 \pm 0.000$ & $\alpha$ Humulene & 1461 & $2.452 \pm 0.006$ \\
\hline$\alpha$ Terpinene & 1017 & $0.396 \pm 0.005$ & Caryophyllene oxide & 1586 & $0.199 \pm 0.004$ \\
\hline p cymene & 1024 & $0.422 \pm 0.006$ & Viridiflorol & 1591 & $4.484 \pm 0.006$ \\
\hline Limonene & 1028 & $1.428 \pm 0.009$ & Methyl Hexadecanoate & 1925 & $0.300 \pm 0.000$ \\
\hline Eucalyptol & 1031 & $17.502 \pm 0.036$ & Manool & 2052 & $0.625 \pm 0.010$ \\
\hline$\gamma$ Terpinene & 1058 & $0.739 \pm 0.007$ & & & \\
\hline Cis Sabinenehydrate & 1067 & $0.166 \pm 0.002$ & & & \\
\hline Terpinolene & 1089 & $0.240 \pm 0.003$ & \multicolumn{2}{|c|}{ Total Identified } & $99.310 \pm 0.024$ \\
\hline Linalool & 1100 & $0.214 \pm 0.004$ & \multicolumn{2}{|c|}{ Monoterpenes hydrocarbons } & $17.009 \pm 0.212$ \\
\hline$\alpha$ Thujone & 1105 & $27.169 \pm 0.148$ & \multicolumn{2}{|c|}{ Sesquiterpenes hydrocarbons } & $4.936 \pm 0.004$ \\
\hline$\beta$ Thujone & 1122 & $6.854 \pm 0.014$ & \multicolumn{2}{|c|}{ Oxygenated monoterpenes } & $71.297 \pm 0.254$ \\
\hline trans Sabinol & 1138 & $0.248 \pm 0.000$ & \multicolumn{2}{|c|}{ Oxygenated sesquiterpenes } & $4.683 \pm 0.011$ \\
\hline Camphor & 1144 & $16.909 \pm 0.061$ & \multicolumn{2}{|c|}{ Others } & $1.384 \pm 0.011$ \\
\hline
\end{tabular}

Values $(n=3)$ are means \pm SE. RI represents the retention index relative to n-alkanes on the ZB- 5 column. Bold values represent the main constituents $(>1 \%)$ of the examined essential oils (EOs).

\subsection{Decay Percentage}

Control treated tomatoes and tomatoes coated with $\mathrm{AV}$ and/or sage EO revealed decay symptoms at $0.5 \% \mathrm{EO}$, at 7 days of storage. Following $14 \mathrm{~d}$ of storage both $\mathrm{AV}$ and $\mathrm{EO}$ decreased decay symptoms with more pronounced effects on low EO concentration (i.e., $0.1 \%$ ). However, control decay evaluated as 2.87 based on the 1-5-scale. High EO levels can cause tomato tissue cell damage and decay can be easier developed/initiated [12]. Decay was mainly attributed to the anthracnose rot (triggered by Colletotrichum coccodes) and secondary black spot symptoms (triggered by Alternaria alternata)] as shown in Table 2. The observation of fungal symptoms was the indicative of fruit decay but additional research is required for any other physiological or bacterial symptoms presence. Several studies indicated the antimicrobial capacity of $\mathrm{EO}$ in vitro and/or in fresh commodities $[4,12,15,34,38]$. 
Table 2. Effect of Aloe vera (AV at $10 \%$ ) coating and/or sage essential oil (EO at $0.1 \%$ and $0.5 \%$ ) on tomato fruit decay during storage $\left(11^{\circ} \mathrm{C}, 90 \%\right.$ relative humidity $\left.(\mathrm{RH})\right)$. The degree of infection on fruit was rated using a scale of 1 to 5 (1-clean, no infection; 2-trace infection; 3-slight infection; 4-moderate infection and 5-severe infection).

\begin{tabular}{cccc}
\hline & \multicolumn{3}{c}{ Fruit decay } \\
\hline & Day 0 & Day 7 & Day 14 \\
\hline Control & $1.00 \pm 0.00 *$ & $1.25 \pm 0.13 \mathrm{a}$ & $2.87 \pm 0.17 \mathrm{a}$ \\
$\mathrm{AV}$ & & $1.08 \pm 0.08 \mathrm{ab}$ & $1.42 \pm 0.15 \mathrm{~b}$ \\
$\mathrm{EO}(0.1 \%)$ & & $1.00 \pm 0.00 \mathrm{~b}$ & $1.08 \pm 0.07 \mathrm{c}$ \\
$\mathrm{AV}+\mathrm{EO}(0.1 \%)$ & $1.00 \pm 0.00 \mathrm{~b}$ & $1.00 \pm 0.00 \mathrm{c}$ \\
$\mathrm{EO}(0.5 \%)$ & $1.25 \pm 0.13 \mathrm{a}$ & $1.58 \pm 0.19 \mathrm{~b}$ \\
$\mathrm{AV}+\mathrm{EO}(0.5 \%)$ & & $1.08 \pm 0.07 \mathrm{ab}$ & $1.42 \pm 0.15 \mathrm{~b}$ \\
\hline
\end{tabular}

Values represent the mean of evaluation made on 10 independent fruit per treatment per storage period. Values followed by the same letter in each column do not differ significantly $(p<0.05)$. Symbols of ${ }^{*}$ or $n s$ indicating significance or not, respectively, among controls through storage period.

\subsection{Respiration and Ethylene Production Rates}

The changes in respiration rates and ethylene emission for tomato fruits are presented in Figure 1A,B. Control fruit subjected to low storage temperature $\left(11^{\circ} \mathrm{C}\right)$ had lower respiration rates after 7 days of storage compared to the relevant rates measured at harvest date (day 0 ). Indeed, respiration rates increased throughout the storage period for all the treatments. Therefore, respiration rates were maintained at low EO levels (0.1\%) but were increased (up to $112 \%$ and $77.3 \%$ ) at $0.5 \%$ EO after 7 and 14 days of storage, respectively (Figure 1A). The addition of AV did not affect the respiration rates, being in accordance with previous studies when various $\mathrm{AV}$ concentrations $(0 \%, 5 \%, 10 \%, 15 \%$ and $20 \%$ ) were tested on tomato [6]. In contrast, when higher concentration (i.e., 33\%) of AV was used, respiration rates on AV-treated cherries were lower compared to the control (untreated) fruits [25]. Paladines et al. [24] recorded a decrease in the respiration rate of Aloe-treated cherries, nectarines and plums but non-significant changes were found between control and Aloe-treated peaches, highlighting that the variation on the observations were related to species and/or climate and plant growing conditions. Valero et al. [42] reported that edible coating with AV affects the gas composition during the storage of the fruit, by decreasing the fruit surface permeability to the gases, and resulting in increased $\mathrm{CO}_{2}$ and decreased $\mathrm{O}_{2}$ levels.

Ethylene emission in 10\% AV-treated tomatoes decreased at 7 and 14 days when compared to the control treatment (Figure 1B). Sage EO at $0.5 \%$ increased the ethylene emission at 7 days. The combination of $\mathrm{AV}$ with $\mathrm{EO}$ resulted in ethylene emission decrease at $\mathrm{AV}+0.5 \% \mathrm{EO}$ at $7 \mathrm{~d}$ but this effect did not persist following storage of 14 days, whereas ethylene increased with EO (at $0.1 \%$ and $0.5 \%)$ and $\mathrm{AV}+\mathrm{EO}$ treatments. This increase probably reflects on the induce stress on the fruit and the speed up of the fruit metabolism and ripening process. Ethylene retardation in Aloe-treated stone fruits was previously reported [24,27], being in consistence with the current results for the 7 days of storage.

\subsection{Tomato Quality Parameter and Bioactive Compounds}

As anticipated, in control fruit, the ripening attributes such as color, fruit firmness and ripening index expressed by the TSS/TA ratio changed significantly during the storage period, comparing the initial to final levels after $14 \mathrm{~d}$ of storage. Tomato weight loss was increased with the application of $0.5 \%$ of EO treatment compared to the control or $0.1 \%$-treated tomatoes stored for 7 and 14 days at $11{ }^{\circ} \mathrm{C} / 90 \% \mathrm{RH}$ (Figure 1C). Aloe-coating on tomatoes was not effective as no significant changes were found on weight loss during 7 or 14 days storage comparing to the control and/or EO treated samples (Figure 1C). The low hydrophobic properties of AV component during the edible coating preparation are important to be considered. Contradicting findings have been reported previously, as related to the $\mathrm{AV}$ concentration and commodity. Therefore, Ahmed et al. [43] and Castillo et al. [26] reported weight 
loss decreases in nectarines (treated with $2.5 \%$ gel) and in table grapes (treated with $33 \%$ gel) while Ergun and Satici [23] reported weight loss decrease only for the variety "Granny Smith" but not for the "Red Smith" apples treated up to $10 \% \mathrm{AV}$ gel.

Fruit firmness significantly decreased in control fruits during the entire storage period (Figure 1D). The application of $\mathrm{AV}$ or $\mathrm{AV}+0.1 \%$ EO led to lower softening in tomato following 7 days of storage compared to the control and $\mathrm{AV}+0.5 \%$ EO treatments, but this effect did not persist during the $14 \mathrm{~d}$ of storage. Interestingly, the addition of sage oil itself did not affect fruit firmness. Similar to our findings, Martínez-Romero et al. [25] reported that higher AV concentration $(33 \% v / v)$ substantially decreased the firmness losses ( $\geq 50 \%$ ) during chilled storage in cherries. Furthermore, Dang et al. [44] reported that mangoes maintained firmness when $100 \%$ of AV gel was used at shelf life storage of the fruit. The marked effect observed in previous studies might be related to the higher AV gel ratio and different species used. The edible coating mode of application (dipping vs. spraying, time, temperature and frequency) is also important as the double application of $A$. vera on table grapes was more efficient for fruit firmness maintenance than a single implementation [26].
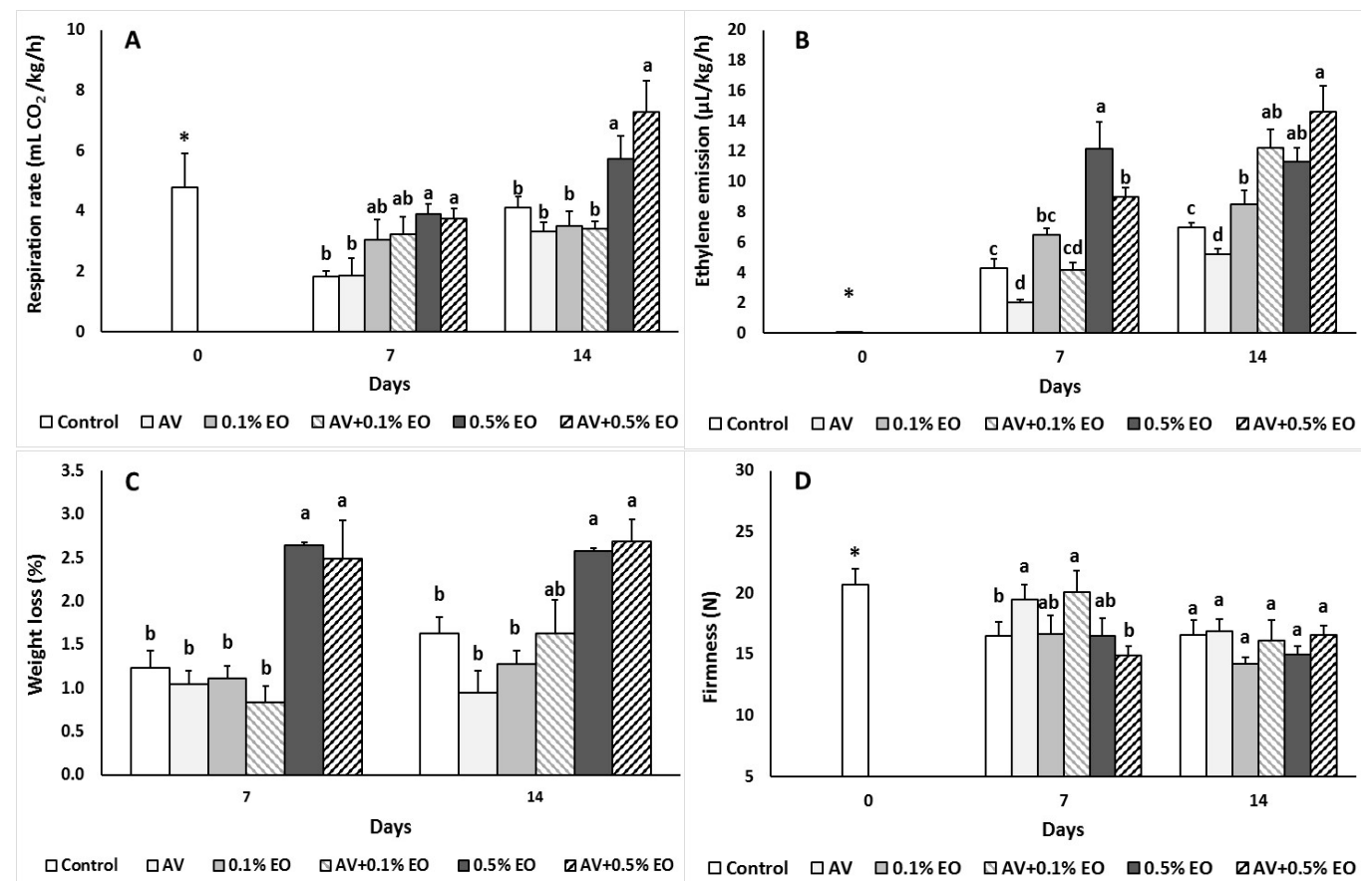

Figure 1. Impacts Aloe vera (AV at $10 \%$ ) coating and/or sage essential oil (EO at $0.1 \%$ and $0.5 \%$ ) on (A) respiration rate $\left(\mathrm{mL} \mathrm{CO}_{2} / \mathrm{kg} / \mathrm{h}\right),(\mathbf{B})$ ethylene emission $(\mu \mathrm{L} / \mathrm{kg} / \mathrm{h}),(\mathbf{C})$ weight loss $(\%)$ and $(\mathbf{D})$ firmness (expressed in Newton) in tomato fruit following storage for 7 and 14 days. Fruit were maintained throughout at $11^{\circ} \mathrm{C}$ and $90 \% \mathrm{RH}$. Values represent mean ( $\pm \mathrm{SE}$ ) of measurements made on eight independent fruit per treatment and storage period. On the columns, significant differences $(p<0.05)$ among treatments are indicated by different Latin letters for different days. Symbols of * or $n s$ indicating significance or not, respectively, among controls through storage period.

The control fruits stored up to 14 days had decreased lightness ( $L^{*}$ value) and increased redness ( $a^{*}$ value), which resulted in increased Chroma values (Figure 2). Fruit lightness increased with the $0.1 \% \mathrm{EO}, 0.5 \% \mathrm{EO}$ and $\mathrm{AV}+0.5 \% \mathrm{EO}$ when compared to control, $\mathrm{AV}$ and $\mathrm{AV}+0.1 \%$ treatments after 7 days of storage (Figure 2A). Fruit redness and chroma decreased with the application of high EO levels (i.e., $0.5 \%$ ) independently of the $\mathrm{AV}$ coating and this was not evident after 14 days of storage (Figure 2B,D). Color hue decreased significantly in all treatments with an exception of the $\mathrm{AV}+0.5 \%$ $\mathrm{EO}$, which was related to the darkening of the fruit (Figure 2C). Color $b^{*}$ values were significantly 
decreased at $0.5 \%$ EO treated fruits compared to the control fruit after 7 days of storage (data not presented).
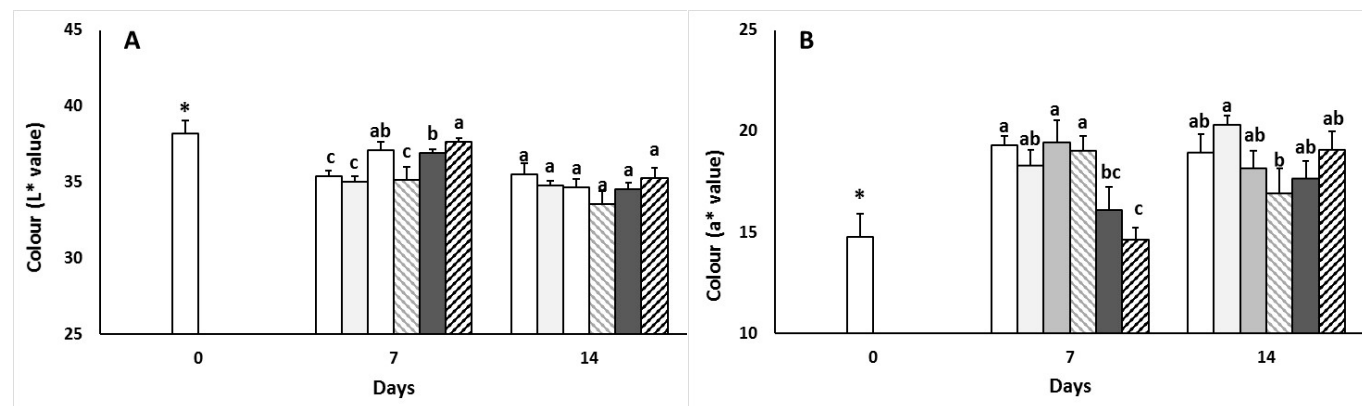

$\square$ Control $\square$ AV $\square 0.1 \%$ EO $\square A V+0.1 \%$ EO $\square 0.5 \%$ EO $\square A V+0.5 \%$ EO
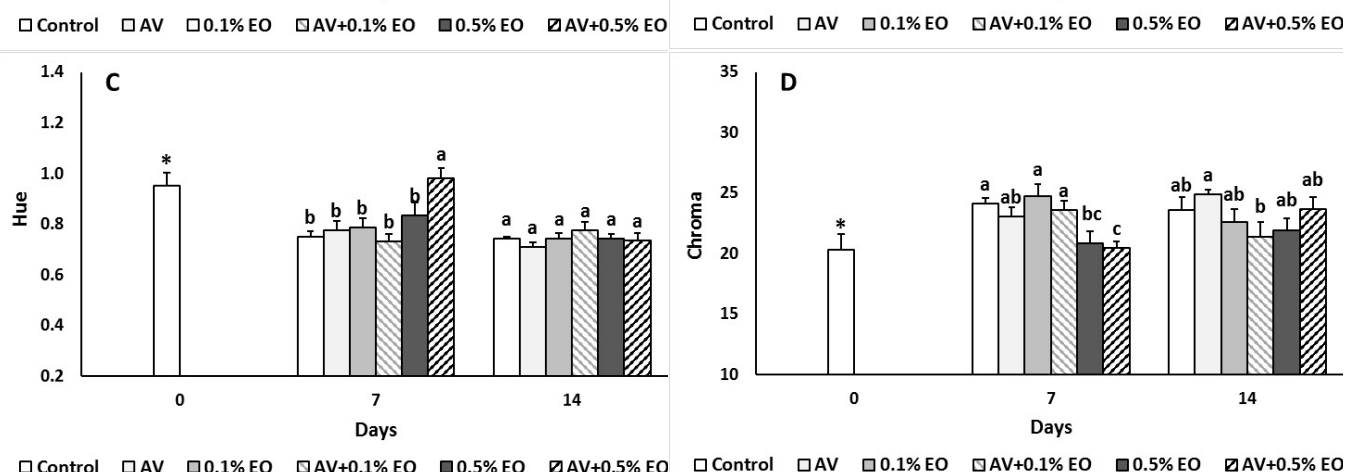

Figure 2. Impacts Aloe vera (AV at 10\%) coating and/or sage essential oil (EO at $0.1 \%$ and $0.5 \%$ ) on (A) $L^{*},(\mathbf{B}) a^{*},(\mathbf{C})$ hue and (D) chroma values in tomato fruit following storage for 7 and 14 days. Fruit were maintained throughout at $11{ }^{\circ} \mathrm{C}$ and $90 \% \mathrm{RH}$. Values represent mean $( \pm \mathrm{SE})$ of measurements made on eight independent fruit per treatment and storage period. On the columns, significant differences $(p<0.05)$ among treatments are indicated by different Latin letters for different days. Symbols of * or $n s$ indicating significance or not, respectively, among controls through storage period.

The TSS values ranged to similar levels at 7 days and significantly decreased $(p<0.05)$ in $0.5 \%$ EO-treated fruits after 14 days of storage compared to the control and AV treatments (Figure 3). The titratable acidity values of AV and/or EO treated fruits significantly decreased $(p<0.01)$ and the ripening index (TSS/TA ratio) was increased compared to the control (un-coated fruits) after 14 days of storage. This indicates that $\mathrm{AV}$ and/or EO treated fruits had increased sweetness compared to the control treatments. Acidity of raspberries subjected with $A$. vera gel did not differ with the untreated fruits after 8 days of storage [45] being in line with the current results for the 7 days of storage.

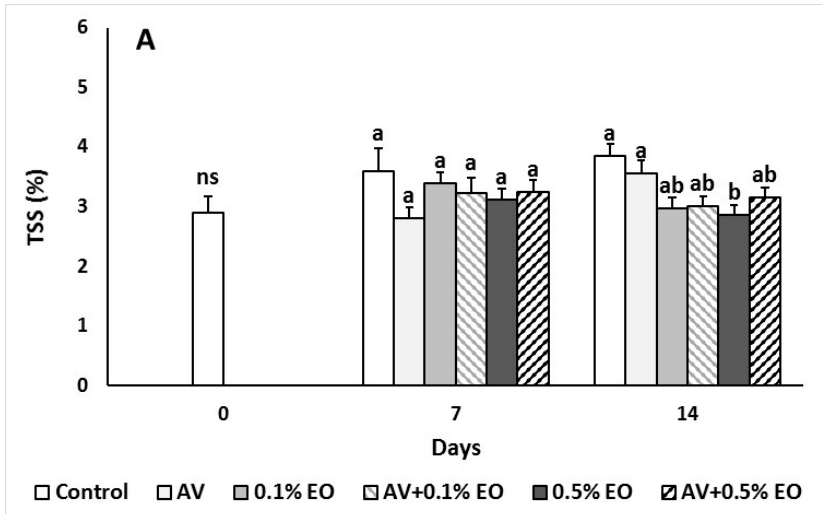

Figure 3. Cont. 

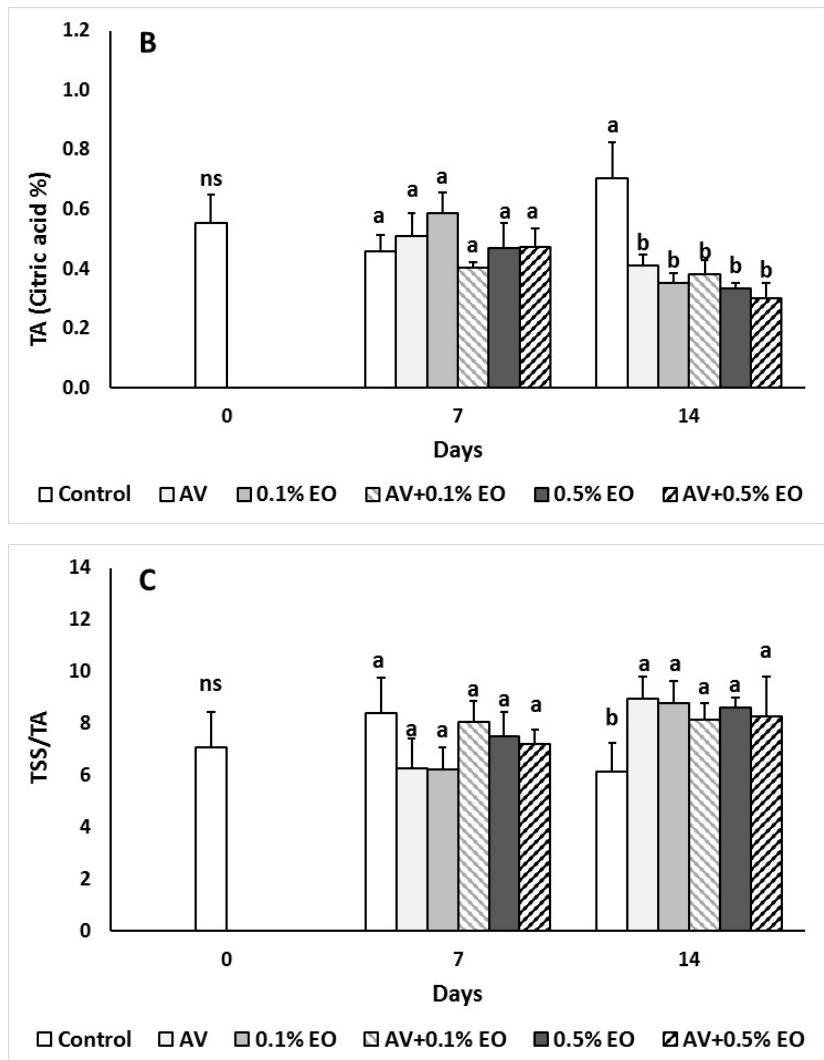

Figure 3. Impacts Aloe vera (AV at $10 \%$ ) coating and/or sage essential oil (EO at $0.1 \%$ and $0.5 \%$ ) on (A) total soluble solids (TSSs), (B) titratable acidity (TA) and (C) ripening index (TSS/TA) in tomato fruit following storage for 7 and 14 days. Fruit were maintained throughout at $11{ }^{\circ} \mathrm{C}$ and $90 \% \mathrm{RH}$. Values represent mean $( \pm \mathrm{SE})$ of measurements made on eight independent fruit per treatment and storage period. On the columns, significant differences $(p<0.05)$ among treatments are indicated by different Latin letters for different days. Symbols of * or $n s$ indicating significance or not, respectively, among controls through storage period.

In tomato fruits the pigments content is changed during fruit development, while the chlorophyll content is reduced during maturation and carotenoids are produced promptly, thus synthesizing the red pigment lycopene and $\beta$-carotene. In the present study, in control fruits, $\beta$-carotene and lycopene content significantly changed the first 7 days of storage, while they remained to similar levels to the control following $14 \mathrm{~d}$ of storage (Figure $4 \mathrm{~A}, \mathrm{~B}$ ). Both $\beta$-carotene and lycopene content were decreased in $10 \% \mathrm{AV}$ and in $\mathrm{AV}+0.5 \% \mathrm{EO}$ (only for $\beta$-carotene) coated fruits when compared with the control at 7 days of storage, while $\beta$-carotene content decreased in $\mathrm{AV}+0.5 \% \mathrm{EO}$ treatment after 14 days of storage (Figure $4 \mathrm{~A}, \mathrm{~B}$ ). When thyme and savory EO applied on peaches and nectarines, carotenoid content was maintained to similar levels with the control fruits [46].

During ripening, ascorbic acid content decreased and this was evidenced for the control fruits during 14 days of storage (Figure 4C). Aloe-coating maintained ascorbic acid to similar levels with the control treatment at 7 days but increased ascorbic acid content following 14 days of storage. Essential oil treated tomatoes at $0.1 \%$ revealed higher ascorbic acid content after 14 days compared to the control treatment. The combination of $\mathrm{AV}$ and EO seemed not to have any effect on ascorbic acid content. Ascorbic acid but also polyphenols have strong antioxidant capacity, and were able to protect against the free radicals and disease development, which confirmed the decreased decay levels found in EO-treated fruits (mainly AV + 0.1\% EO) that had high ascorbic acid levels at 14 days of storage. Aminifard and Mohammadi [47] reported that when EO from ammi (Carum copticum) and 
anise (Pimpinella anisum) applied on tomatoes, fruits revealed higher ascorbic acid content compared to untreated tomatoes.
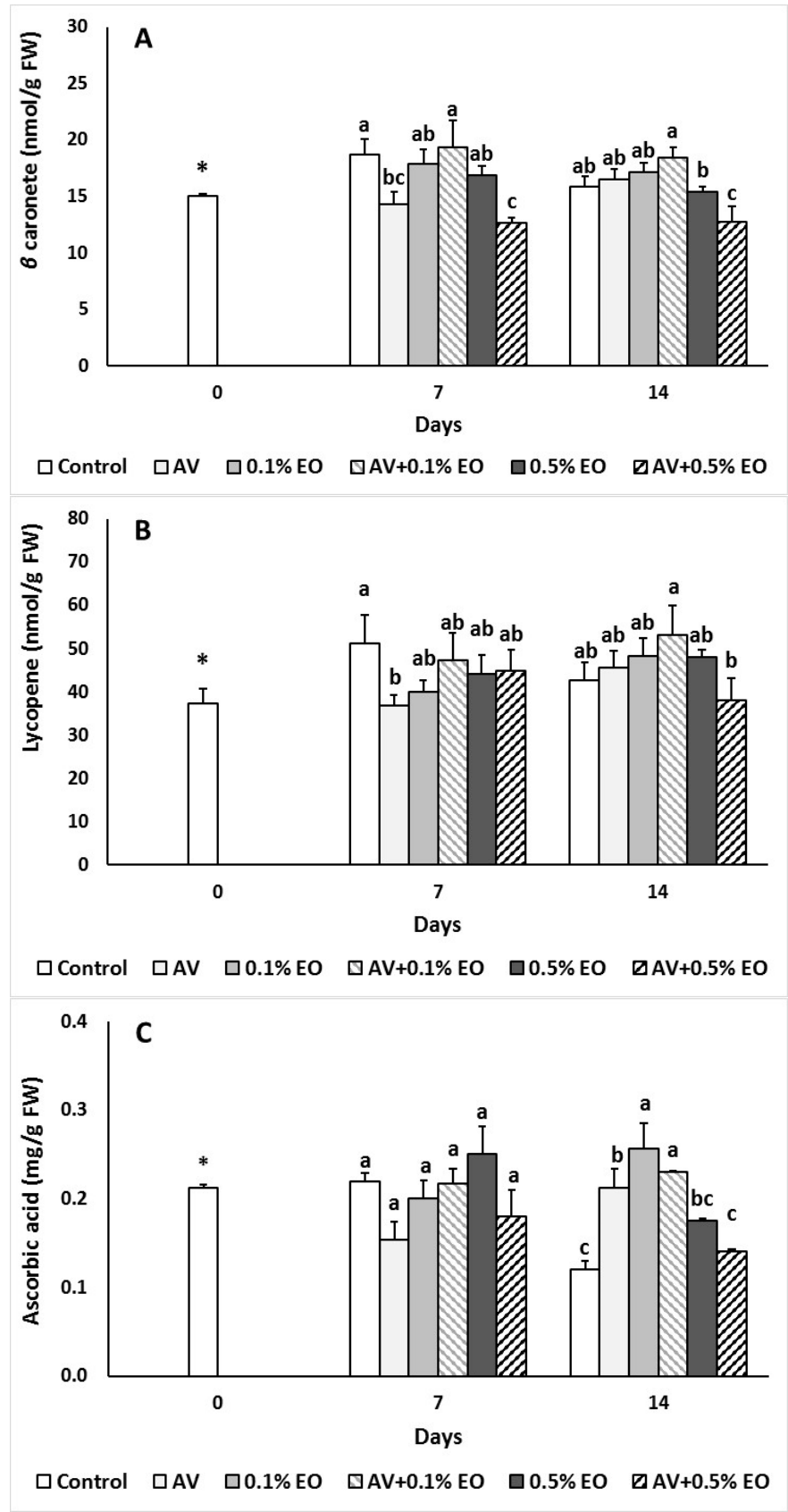

Figure 4. Impacts Aloe vera (AV at $10 \%$ ) coating and/or sage essential oil (EO at $0.1 \%$ and $0.5 \%$ ) on (A) $\beta$-carotene (nmol/g FW), (B) lycopene (nmol/g FW) and (C) ascorbic acid (mg/g FW) in tomato fruit following storage for 7 and 14 days. Fruit were maintained throughout at $11{ }^{\circ} \mathrm{C}$ and $90 \% \mathrm{RH}$. Values represent mean $( \pm \mathrm{SE})$ of measurements made on eight independent fruit per treatment and storage period. On the columns, significant differences $(p<0.05)$ among treatments are indicated by different Latin letters for different days. Symbols of * or $n s$ indicating significance or not, respectively, among controls through storage period.

Polyphenols and antioxidant activity, indicated by the DPPH and FRAP assay, are shown in Figure 5. At harvesting day, the content of total phenolics was $0.353 \pm 0.021 \mu \mathrm{mol} \mathrm{GAE}$ per $g$ fresh weight (Figure 5A). Both total phenolics and antioxidant activity at 7 days of storage were remained to similar 
levels as the day 0 for both coated and uncoated fruits. Following 14 days of storage, total phenolics increased in $0.1 \% \mathrm{EO}, \mathrm{AV}+0.1 \% \mathrm{EO}$ and in $\mathrm{AV}+0.5 \% \mathrm{EO}$ treatments (Figure $5 \mathrm{~A}$ ). Antioxidant activity (DPPH and FRAP) increased at $0.1 \%$ EO but remained unchanged at $0.5 \% \mathrm{EO}$ treatment comparing to the control fruits (Figure 5B,C). Previous reports on cherries [25], table grapes [20,26], nectarines [43] and strawberries [21] with AV application reflected the delaying of the postharvest processes and changes to the parameters related to fruit quality with the inhibition of ethylene production.
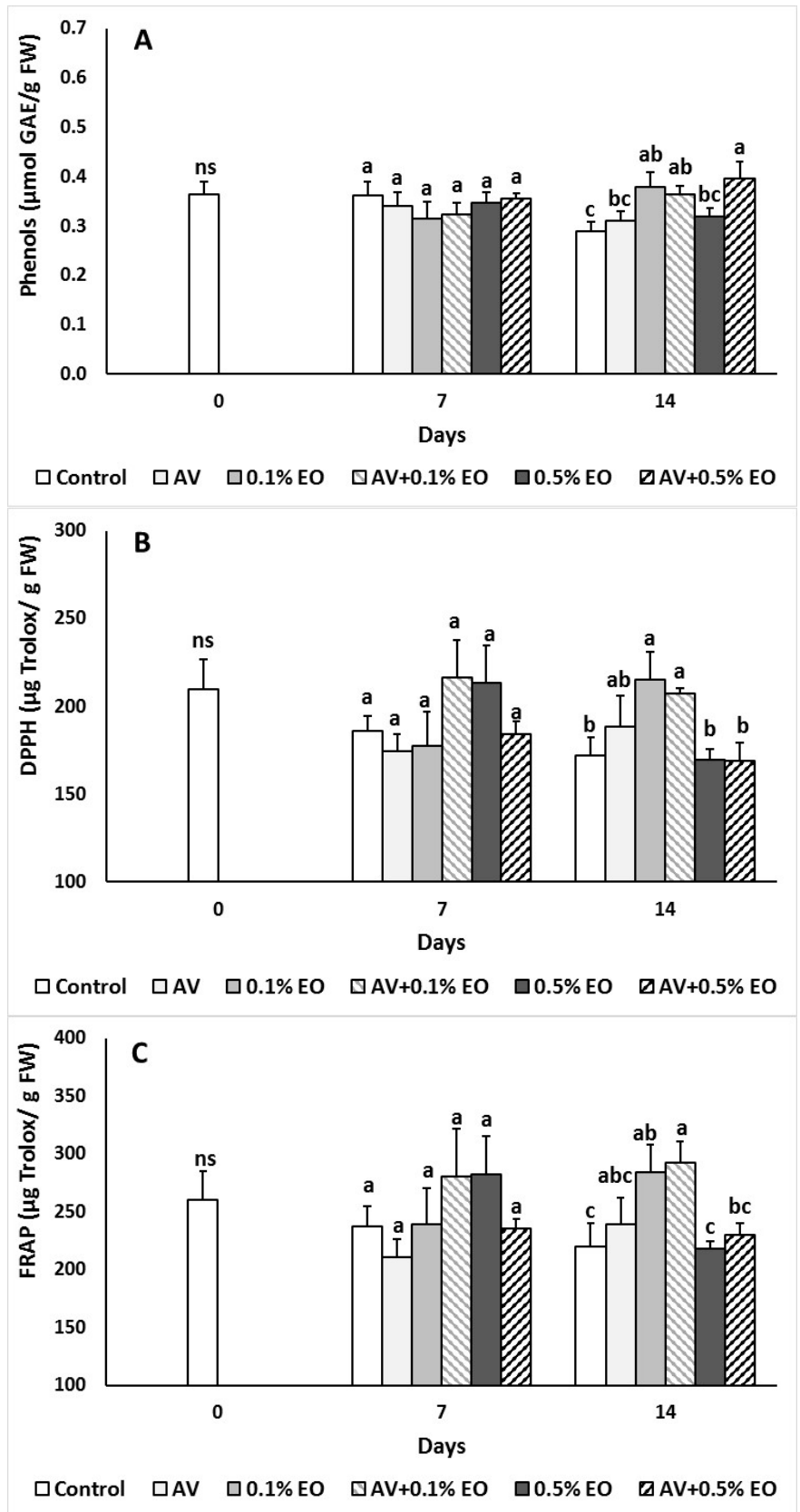

Figure 5. Impacts Aloe vera (AV at $10 \%$ ) coating and/or sage essential oil (EO at $0.1 \%$ and $0.5 \%$ ) on (A) total phenolics ( $\mu$ mol GAE/g FW) and antioxidant activity (mg Trolox/g FW) of (B) DPPH and (C) FRAP in tomato fruit following storage for 7 and 14 days. Fruit were maintained throughout at 11 ${ }^{\circ} \mathrm{C}$ and $90 \%$ RH. Values represent mean $( \pm \mathrm{SE})$ of measurements made on eight independent fruit per treatment and storage period. On the columns, significant differences $(p<0.05)$ among treatments are indicated by different Latin letters for different days. Symbols of * or $n s$ indicating significance or not, respectively, among controls through storage period. 
Heat maps based on the relative expression of quality changes in tomato fruit subjected to $A$. vera (AV at $10 \%$ ) coating and/or sage essential oil (EO at $0.1 \%$ and $0.5 \%$ ) are presented in Figure 6 . At 7 days of storage, AV coating retarded the expression of most of the quality parameters (Figure 6A). Application of $0.1 \%$ of EO enhanced phenolics, antioxidants, acidity and color values but decreased fruit firmness and ripening index (TSS/TA), which were increased at the AV $+0.1 \%$ EO treatment. Fruits subjected to high EO levels of $0.5 \%$ revealed increased metabolism as indicated with increased weight loss, ethylene emission and when combined with AV (AV + 0.5\% EO), additionally, respiration and fruit darkness (hue value) increased.
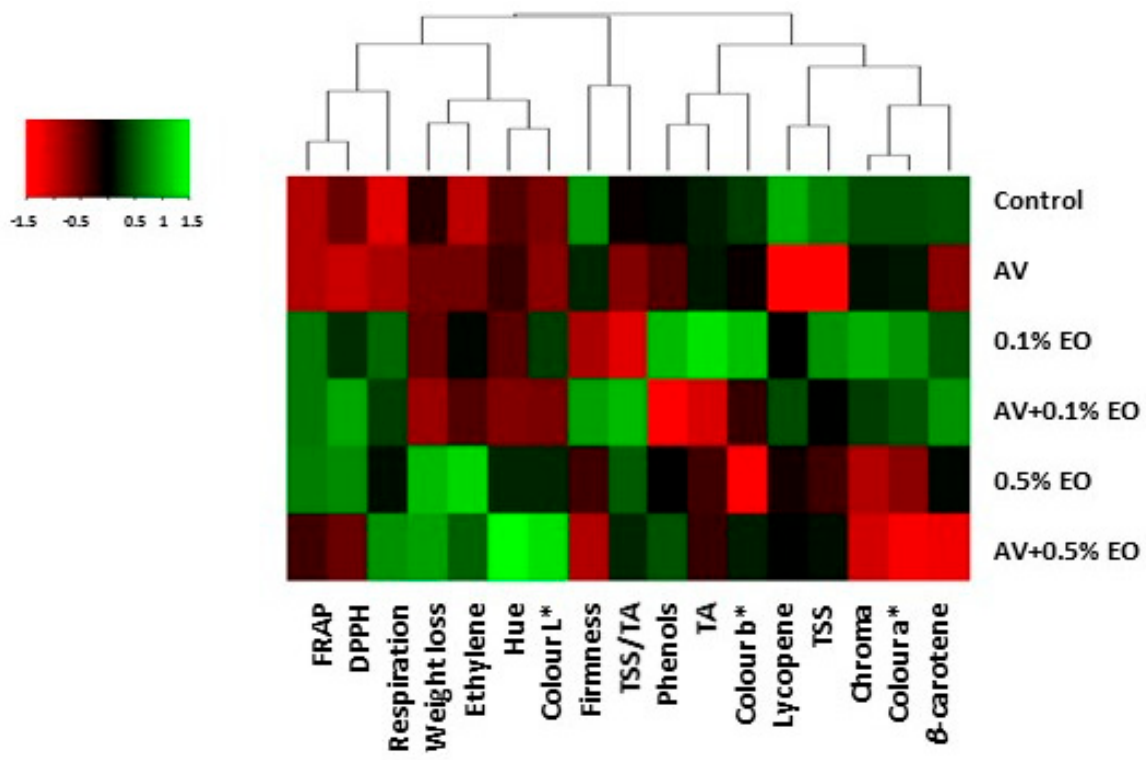

(A)
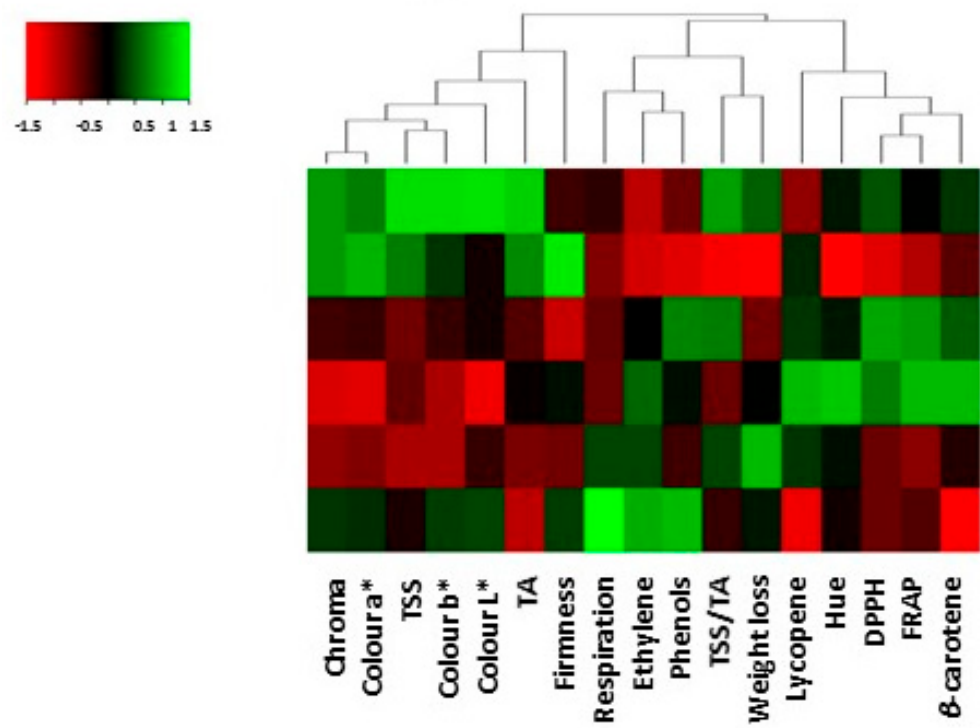

(B)

Figure 6. Quality changes in tomato fruit when subjected to Aloe vera (AV at $10 \%$ ) coating and/or sage essential oil (EO at $0.1 \%$ and $0.5 \%$ ). Heat map representing relative expression of postharvest performance elicited in tomato fruit following (A) 7 days and (B) 14 days of storage as compared to control fruits.

Following 14 days of storage, AV-treated fruits increased color $\mathrm{a}^{*}$ and firmness and decreased TSS/TA, weight loss, antioxidant capacity (DPPH) and $\beta$-carotene (Figure 6B). Low levels of EO $(0.1 \%)$ 
suppressed color values, TSS, TA and firmness. Similar to 7 days, tomatoes subjected to $0.5 \%$ EO for 14 days accelerated metabolic processes with increased respiration and ethylene production as well as increased expression of phenolics.

\subsection{Sensory Evaluation}

Sensory assessment obtained substantial differences between treatments that could be identified by almost all jurors. Following 7 days of storage, jurors preferred $\mathrm{AV}$ and $0.1 \%$ EO treated fruit with $30 \%$ and followed by control and $\mathrm{AV}+0.1 \%$ EO treated fruits with $20 \%$. In case of 14 days of storage, jurors preferred $\mathrm{AV}, 0.1 \% \mathrm{EO}$, control and $\mathrm{AV}+0.1 \% \mathrm{EO}$ with $40 \%, 30 \%, 20 \%$ and $10 \%$, respectively. Interestingly, no preference was for high-EO (i.e., $0.5 \% \mathrm{EO}$ ) treated tomatoes, revealing the worst scores on sensory attributes. Of those expressing a preference to AV-treated fruits, this was related to the increased score of the texture and marketability when compared to the control fruits (Table 3). Low levels (at $0.1 \%$ ) of EO-treated fruits had increased scores for appearance, aroma, texture and marketability while the combination of $\mathrm{AV}$ and $0.1 \% \mathrm{EO}$ either maintained or decreased the relevant scores of texture and marketability of the single EO use, when compared to the control treatment. The increased EO levels mirrored the decreased scores of the sensory evaluation. Only products that meet consumer's expectations are acceptable at the market interface, highlighting the importance of sensory evaluations especially when vaporized sanitation means are involved. Similar to our findings, Valverde et al. [19] and Martínez-Romero et al. [25] reported that AV gel-coated grapes and sweet cherries delayed ripening process by retarding organoleptic attributes with high sensory panel acceptance.

Table 3. Quantitative analysis of the impacts of Aloe vera (AV at $10 \%$ ) coating and/or sage essential oil (EO at $0.1 \%$ and $0.5 \%$ ) on sensory attributes of tomato fruit after 7 and 14 days of storage. Fruit were maintained throughout at $11{ }^{\circ} \mathrm{C}$ and $90 \% \mathrm{RH}$. Values (\%) represent mean ( \pm SE) of assessments made by 10 panelists per treatment.

\begin{tabular}{ccccccc}
\hline & Appearance & Aroma & Texture & Marketability & Preference \\
\hline Day 7 & Control & $58 \pm 3.6 \mathrm{~b}$ & $66 \pm 3.1 \mathrm{~b}$ & $58 \pm 3.6 \mathrm{c}$ & $56 \pm 2.6 \mathrm{~b}$ & 20 \\
& AV & $66 \pm 5.2 \mathrm{ab}$ & $70 \pm 4.4 \mathrm{ab}$ & $76 \pm 4.0 \mathrm{ab}$ & $74 \pm 4.2 \mathrm{a}$ & 30 \\
& EO $(0.1 \%)$ & $76 \pm 4.0 \mathrm{a}$ & $78 \pm 3.6 \mathrm{a}$ & $70 \pm 3.3 \mathrm{~b}$ & $70 \pm 3.3 \mathrm{a}$ & 30 \\
& AV + EO $(0.1 \%)$ & $62 \pm 4.6 \mathrm{~b}$ & $64 \pm 2.6 \mathrm{~b}$ & $80 \pm 2.9 \mathrm{a}$ & $78 \pm 3.6 \mathrm{a}$ & 20 \\
& EO $(0.5 \%)$ & $40 \pm 2.9 \mathrm{c}$ & $28 \pm 3.2 \mathrm{~d}$ & $44 \pm 2.6 \mathrm{~d}$ & $22 \pm 2.0 \mathrm{c}$ & 0 \\
& AV + EO $(0.5 \%)$ & $38 \pm 3.5 \mathrm{c}$ & $26 \pm 3.1 \mathrm{~d}$ & $34 \pm 3.1 \mathrm{e}$ & $24 \pm 2.6 \mathrm{c}$ & 0 \\
\hline Day 14 & Control & $52 \pm 3.2 \mathrm{c}$ & $66 \pm 3.1 \mathrm{ab}$ & $48 \pm 3.2 \mathrm{~b}$ & $52 \pm 3.2 \mathrm{~b}$ & 20 \\
& AV & $62 \pm 3.5 \mathrm{~b}$ & $68 \pm 3.2 \mathrm{ab}$ & $66 \pm 3.1 \mathrm{a}$ & $64 \pm 2.6 \mathrm{a}$ & 40 \\
& EO $(0.1 \%)$ & $72 \pm 3.2 \mathrm{a}$ & $72 \pm 3.2 \mathrm{a}$ & $62 \pm 3.6 \mathrm{a}$ & $70 \pm 3.3 \mathrm{a}$ & 30 \\
& AV + EO $(0.1 \%)$ & $58 \pm 3.6 \mathrm{bc}$ & $60 \pm 0.0 \mathrm{~b}$ & $62 \pm 4.6 \mathrm{a}$ & $68 \pm 3.2 \mathrm{a}$ & 10 \\
EO $(0.5 \%)$ & $34 \pm 3.1 \mathrm{~d}$ & $30 \pm 3.3 \mathrm{c}$ & $46 \pm 3.1 \mathrm{~b}$ & $22 \pm 2.0 \mathrm{c}$ & 0 \\
& AV + EO $(0.5 \%)$ & $34 \pm 3.1 \mathrm{~d}$ & $28 \pm 3.2 \mathrm{c}$ & $38 \pm 2.0 \mathrm{~b}$ & $20 \pm 0.0 \mathrm{c}$ & 0 \\
\hline
\end{tabular}

Values followed by the same letter in each column for each day do not differ significantly $(p<0.05)$.

\section{Conclusions}

The present findings shows both $\mathrm{AV}$ and EO decreased decay symptoms with more pronounced effects on low EO concentration (i.e., $0.1 \%$ ) after 14 days of storage. The examined treatments affected fruit metabolism as tomatoes treated with high levels $(0.5 \%)$ of EO increased respiration rates, ethylene emission, weight loss and ascorbic acid content but decreased tomatoes redness, chroma, TSS, TA, $\beta$-carotene and lycopene content. Indeed, low $(0.1 \%)$ levels of EO maintained or improved fruit quality attributes during storage, and were better preserved by the treatment at 7 days rather than 14 days. AV coating did not affect respiration rates, weight loss, ascorbic acid and TSS but decreased ethylene emission, TA, $\beta$-carotene, lycopene and maintained fruit firmness. Total phenolics and antioxidant 
activity were maintained or increased during storage for $\mathrm{AV}$ and/or EO treatments. Sensory evaluation revealed preference on $\mathrm{AV}$ and $0.1 \% \mathrm{EO}$ with increased scores for appearance, aroma, texture and marketability while the combination of $\mathrm{AV}$ and $0.1 \% \mathrm{EO}$ either maintained or decreased the relevant scores of the single EO use. Therefore, $0.1 \% \mathrm{EO}$ and $\mathrm{AV}+0.1 \% \mathrm{EO}$ showed the best results for postharvest storage of tomatoes at $11^{\circ} \mathrm{C} / 90 \% \mathrm{RH}$. More studies are needed for the coating properties related to hydrophobic improvement of $A$. vera, possible multiple coating application and examining any combination of EO and ethylene inhibitor/retardant means such as 1-MCP and methyl jasmonate. The underlying relationship between $A$. vera gel and antioxidant capacity in tomatoes needs to be further investigated.

Author Contributions: Conceptualization, N.T.; methodology, N.T. and P.X.; software, P.X.; validation, A.C. and N.T.; formal analysis, A.C.; investigation, A.C., P.X. and N.T.; resources, N.T.; data curation, A.C.; writing-original draft preparation, A.C. and P.X.; writing-review and editing, N.T.; visualization, N.T.; supervision, N.T.; project administration, N.T.; funding acquisition, N.T.

Funding: This research was funded by Cyprus University of Technology Open Access Author Fund.

Conflicts of Interest: The authors declare no conflict of interest.

\section{References}

1. Ayari, A.; Achir, N.; Servent, A.; Ricci, J.; Brat, P. Development of a nutritional profile predicting tool for fresh and processed tomato-based products. Int. J. Food Sci. Technol. 2015, 50, 1598-1606. [CrossRef]

2. Narváez-Ortiz, W.A.; Becvort-Azcurra, A.A.; Fuentes-Lara, L.O.; Benavides-Mendoza, A.; Valenzuela-García, J.R.; González-Fuentes, J.A. Mineral composition and antioxidant status of tomato with application of selenium. Agronomy 2018, 8, 185. [CrossRef]

3. Casals, J.; Rivera, A.; Sabaté, J.; del Castillo, R.R.; Simó, J. Cherry and fresh market tomatoes: Differences in chemical, morphological, and sensory traits and their implications for consumer acceptance. Agronomy 2019, 9, 9. [CrossRef]

4. Tzortzakis, N.G. Maintaining postharvest quality of fresh produce with volatile compounds. Innov. Food Sci. Emerg. Technol. 2007, 8, 111-116. [CrossRef]

5. Zapata, P.J.; Guillén, F.; Martínez-Romero, D.; Castillo, S.; Valero, D.; Serrano, M. Use of alginate or zein as edible coatings to delay postharvest ripening process and to maintain tomato (Solanum lycopersicon Mill) quality. J. Sci. Food Agric. 2008, 88, 1287-1293. [CrossRef]

6. Chrysargyris, A.; Nikou, A.; Tzortzakis, N. Effectiveness of Aloe vera gel coating for maintaining tomato fruit quality. N. Z. J. Crop Hortic. Sci. 2016, 44, 203-217. [CrossRef]

7. Castro, L.R.; Vigneault, C.; Charles, M.T.; Cortez, L.A.B. Effect of cooling delay and cold-chain breakage on 'Santa Clara' tomato. J. Food Agric. Environ. 2005, 3, 49-54.

8. Brummell, D.A.; Harpster, M.H. Cell wall metabolism in fruit softening and quality and its manipulation in transgenic plants. Plant Mol. Biol. 2001, 47, 311-340. [CrossRef]

9. Osei, M.K.; Danquah, A.; Blay, E.T.; Danquah, E.; Adu-Dapaah, H. An overview of tomato fruit-ripening mutants and their use in increasing shelf life of tomato fruits. Afr. J. Agric. Res. 2017, 12, 3520-3528.

10. Spotts, R.A.; Peters, B.B. Chlorine and chlorine dioxide for control of d' Anjou pear decay. Plant Dis. 1980, 64, 1095-1097. [CrossRef]

11. Romanazzi, G.; Feliziani, E.; Sivakumar, D. Chitosan, a biopolymer with triple action on postharvest decay of fruit and vegetables: Eliciting, antimicrobial and film-forming properties. Front. Microbiol. 2018, 9, 1-9. [CrossRef] [PubMed]

12. Tzortzakis, N.G. Essential oil: Innovative tool to improve the preservation of fresh produce-A review. Fresh Prod. 2009, 3, 87-97.

13. Tzortzakis, N.; Chrysargyris, A. Postharvest ozone application for the preservation of fruits and vegetables. Food Rev. Int. 2017, 33, 270-315. [CrossRef]

14. Usall, J.; Ippolito, A.; Sisquella, M.; Neri, F. Physical treatments to control postharvest diseases of fresh fruits and vegetables. Postharvest Biol. Technol. 2016, 122, 30-40. [CrossRef]

15. Stavropoulou, A.; Loulakakis, K.; Magan, N.; Tzortzakis, N. Origanum dictamnus oil vapour suppresses the development of grey mould in eggplant fruit in vitro. BioMed Res. Int. 2014, 2014, 1-11. [CrossRef] 
16. Droby, S.; Wisniewski, M.; Teixidó, N.; Spadaro, D.; Jijakli, M.H. The science, development, and commercialization of postharvest biocontrol products. Postharvest Biol. Technol. 2016, 122, 22-29. [CrossRef]

17. Mahfoudhi, N.; Chouaibi, M.; Hamdi, S. Effectiveness of almond gum trees exudate as a novel edible coating for improving postharvest quality of tomato (Solanum lycopersicum L.) fruits. Food Sci. Technol. Int. 2014, 20, 33-43. [CrossRef]

18. López-Palestina, C.U.; Aguirre-Mancilla, C.L.; Raya-Pérez, J.C.; Ramírez-Pimentel, J.G.; Gutiérrez-Tlahque, J.; Hernández-Fuentes, A.D. The effect of an edible coating with tomato oily extract on the physicochemical and antioxidant properties of garambullo (Myrtillocactus geometrizans) fruits. Agronomy 2018, 8, 248. [CrossRef]

19. Valverde, J.M.; Valero, D.; Martínez-Romero, D.; Guillén, F.; Castillo, S.; Serrano, M. Novel edible coating based on Aloe vera gel to maintain table grape quality and safety. J. Agric. Food Chem. 2005, 53, 7807-7813. [CrossRef]

20. Serrano, M.; Valverde, J.M.; Guillén, F.; Castillo, S.; Martínez-Romero, D.; Valero, D. Use of Aloe vera gel coating preserves the functional properties of table grapes. J. Agric. Food Chem. 2006, 54, 3882-3886. [CrossRef]

21. Singh, D.B.; Rajbir, S.; Kingsly, A.R.P.; Sharma, R.R. Effect of Aloe vera coatings on fruit quality and storability of strawberry (Fragaria $\times$ ananassa). Indian J. Agric. Sci. 2011, 81, 407-412.

22. Chauhan, O.P.; Nanjappa, C.; Ashok, N.; Ravi, N.; Roopa, N.; Raju, P.S. Shellac and Aloe vera gel based surface coating for shelf life extension of tomatoes. J. Food Sci. Technol. 2013, 52, 1200-1205. [CrossRef] [PubMed]

23. Ergun, M.; Satici, F. Use of Aloe vera gel as biopreservative for "Granny Smith" and "Red Chief" apples. J. Anim. Plant Sci. 2012, 22, 363-368.

24. Paladines, D.; Valero, D.; Valverde, J.M.; Díaz-Mula, H.; Serrano, M.; Martínez-Romero, D. The addition of rosehip oil improves the beneficial effect of Aloe vera gel on delaying ripening and maintaining postharvest quality of several stonefruit. Postharvest Biol. Technol. 2014, 92, 23-28. [CrossRef]

25. Martínez-Romero, D.; Alburquerque, N.; Valverde, J.M.; Guillén, F.; Castillo, S.; Valero, D.; Serrano, M. Postharvest sweet cherry quality and safety maintenance by Aloe vera treatment: A new edible coating. Postharvest Biol. Technol. 2006, 39, 93-100. [CrossRef]

26. Castillo, S.; Navarro, D.; Zapata, P.J.; Guillén, F.; Valero, D.; Serrano, M.; Martínez-Romero, D. Antifungal efficacy of Aloe vera in vitro and its use as a preharvest treatment to maintain postharvest table grape quality. Postharvest Biol. Technol. 2010, 57, 183-188. [CrossRef]

27. Navarro, D.; Díaz-Mula,H.M.; Guillén, F.; Zapata, P.J.; Castillo, S.; Serrano, M.; Valero, D.; Martínez-Romero, D. Reduction of nectarine decay caused by Rhizopus stolonifer, Botrytis cinerea and Penicillium digitatum with Aloe vera gel alone or with the addition of thymol. Int. J. Food Microbiol. 2011, 151, 241-246. [CrossRef] [PubMed]

28. Nejatzadeh-Barandozi, F. Antibacterial activities and antioxidant capacity of Aloe vera. Org. Med. Chem. Lett. 2013, 3, 5. [CrossRef]

29. Zapata, P.J.; Navarro, D.; Guillén, F.; Castillo, S.; Martínez-Romero, D.; Valero, D.; Serrano, M. Characterisation of gels from different Aloe spp. as antifungal treatment: Potential crops for industrial applications. Ind. Crop. Prod. 2013, 42, 223-230. [CrossRef]

30. Morillon, V.; Debeaufort, F.; Blond, G.; Capelle, M.; Voilley, A. Factors affecting the moisture permeability of lipid-based edible films: A review. Crit. Rev. Food Sci. Nutr. 2002, 42, 67-89. [CrossRef]

31. Machmudah, S.; Kawahito, Y.; Sasaki, M.; Goto, M. Supercritical $\mathrm{CO}_{2}$ extraction of rosehip seed oil: Fatty acids composition and process optimization. J. Supercrit. Fluids 2007, 41, 421-428. [CrossRef]

32. Chrysargyris, A.; Xylia, P.; Botsaris, G.; Tzortzakis, N. Antioxidant and antibacterial activities, mineral and essential oil composition of spearmint (Mentha spicata L.) affected by the potassium levels. Ind. Crop. Prod. 2017, 103, 202-212. [CrossRef]

33. Xylia, P.; Chrysargyris, A.; Botsaris, G.; Tzortzakis, N. Potential application of spearmint and lavender essential oils for assuring endive quality and safety. Crop Prot. 2017, 102, 94-103. [CrossRef]

34. Tzortzakis, N.; Chrysargyris, A.; Sivakumar, D.; Loulakakis, K. Vapour or dipping applications of methyl jasmonate, vinegar and sage oil for pepper fruit sanitation towards grey mould. Postharvest Biol. Technol. 2016, 118, 120-127. [CrossRef]

35. Lopez-Reyes, J.G.; Spadaro, D.; Prelle, A.; Garibaldi, A.; Gullino, M.L. Efficacy of plant essential oils on postharvest control of rots caused by fungi on different stone fruits in vivo. J. Food Prot. 2013, 76, 631-639. [CrossRef] 
36. Chrysargyris, A.; Papakyriakou, E.; Petropoulos, S.A.; Tzortzakis, N. The combined and single effect of salinity and copper stress on growth and quality of Mentha spicata plants. J. Hazard. Mater. 2019, 368, 584-593. [CrossRef]

37. Tzortzakis, N.; Singleton, I.; Barnes, J. Impact of low-level atmospheric ozone-enrichment on black spot and anthracnose rot of tomato fruit. Postharvest Biol. Technol. 2008, 47, 1-9. [CrossRef]

38. Xylia, P.; Clark, A.; Chrysargyris, A.; Romanazzi, G.; Tzortzakis, N. Quality and safety attributes on shredded carrots by using Origanum majorana and ascorbic acid. Postharvest Biol. Technol. 2019, 155, 120-129. [CrossRef]

39. AOAC. Official Methods of Analysis, 18th ed.; AOAC: Gaithersburg, MD, USA, 2007.

40. Nagata, M.; Yamashita, I. Simple method for simultaneous determination of chlorophyll and carotenoids in tomato fruit. Nippon Shokuhin Kogyo Gakkaish 1992, 39, 925-928. [CrossRef]

41. Tzortzakis, N.G.; Tzanakaki, K.; Economakis, C.D. Effect of origanum oil and vinegar on the maintenance of postharvest quality of tomato. Food Nutr. Sci. 2011, 2, 974-982. [CrossRef]

42. Valero, D.; Díaz-Mula, H.M.; Zapata, P.J.; Guillén, F.; Martínez-Romero, D.; Castillo, S.; Serrano, M. Effects of alginate edible coating on preserving fruit quality in four plum cultivars during postharvest storage. Postharvest Biol. Technol. 2013, 77, 1-6. [CrossRef]

43. Ahmed, M.J.; Singh, Z.; Khan, A.S. Postharvest Aloe vera gel-coating modulates fruit ripening and quality of "Arctic Snow" nectarine kept in ambient and cold storage. Int. J. Food Sci. Technol. 2009, 44, 1024-1033. [CrossRef]

44. Dang, K.T.H.; Singh, Z.; Swinny, E.E. Edible coatings influence fruit ripening, quality, and aroma biosynthesis in mango fruit. J. Agric. Food Chem. 2008, 56, 1361-1370. [CrossRef] [PubMed]

45. Hassanpour, H. Effect of Aloe vera gel coating on antioxidant capacity, antioxidant enzyme activities and decay in raspberry fruit. LWT-Food Sci. Technol. 2015, 60, 495-501. [CrossRef]

46. Santoro, K.; Maghenzani, M.; Chiabrando, V.; Bosio, P.; Gullino, M.L.; Spadaro, D.; Giacalone, G. Thyme and savory essential oil vapor treatments control brown rot and improve the storage quality of peaches and nectarines, but could favor gray mold. Foods 2018, 7, 7. [CrossRef]

47. Aminifard, M.H.; Mohammadi, S. Effect of essential oils on postharvest decay and quality factors of tomato in vitro and in vivo conditions. Arch. Phytopathol. Plant Prot. 2012, 45, 1280-1285. [CrossRef] 